\title{
10
}

\section{Measuring the Purpose Strength}

\author{
Alvaro Lleo, Carlos Rey, and Nuria Chinchilla
}

In the preceding chapters, a new logic for the twenty-first-century organization was proposed - the logic of leading based on a shared and common business purpose, one that captures the mind, captivates the heart, and guides the day-to-day routines of every individual in the organization. In view of this new logic, though, the question becomes, how are leaders to assess whether or not the purpose of the business is truly common and deeply shared?

To be able to answer such questions, it is crucial we have a perspective that allows for the gathering of our employees' thoughts and feelings, a system that assesses the organization's health, and its areas for improvement upon which to base our actions. These actions will be the more effective the better the assessment systems in which we make our diagnosis. It is not only about measuring discreet variables, but also knowing how they are related to each other,

\author{
A. Lleo $(\triangle)$ \\ University of Navarra, TECNUN School of Engineering, \\ San Sebastian, Spain \\ e-mail: alleo@tecnun.es \\ C. Rey \\ Universitat Internacional de Catalunya, \\ Barcelona, Spain \\ e-mail: carlosrey@uic.es \\ N. Chinchilla \\ IESE Business School, University of Navarra, \\ Barcelona, Spain \\ e-mail: chinchilla@iese.edu




\section{PURPOSE STRENGTH MODEL}

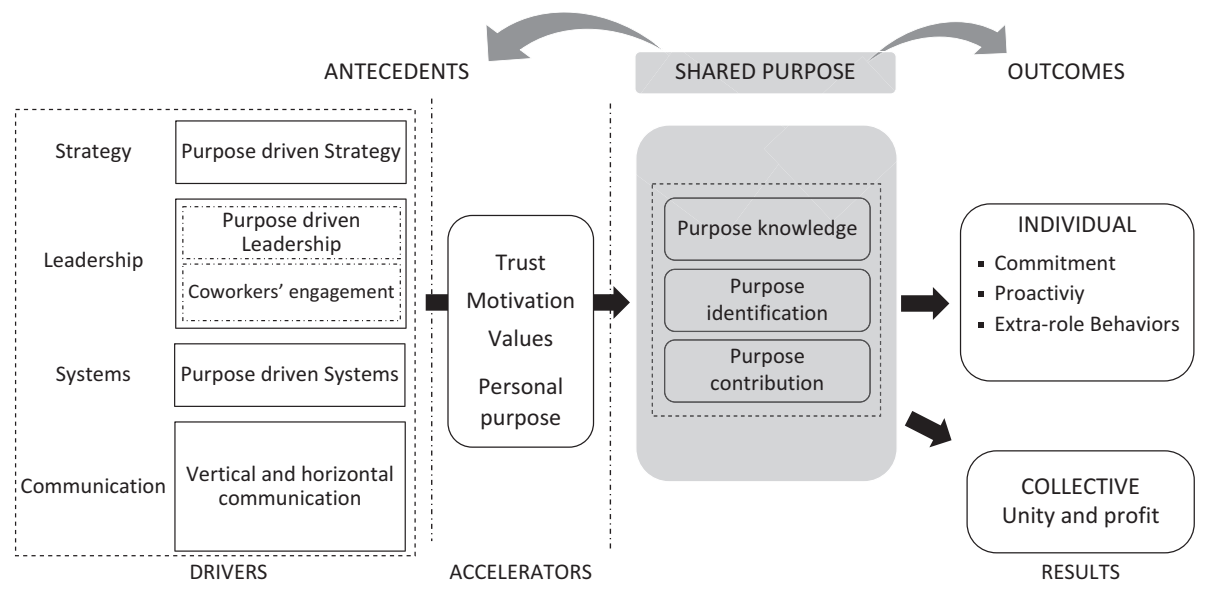

Fig. 10.1 The Purpose Strength Model

identifying the causes of some of them, the effects of others, and which variables accelerate the relationships among them.

In order to meet this threefold objective of assessing, diagnosing and enhancing the purpose strength in an organization, we developed the Purpose Strength Model, shown in Fig. 10.1, which establishes the basis for the development of a measuring tool.

We begin by focusing on the core of the new paradigm (shown in the middle of the diagram below), the shared purpose. Based on this paradigm, we then integrate those remaining variables that play a significant role. We will firstly identify the main consequences. We further identify the main antecedents on which it is possible to act in order to design an organization around a shared purpose (drivers) and, also, the variables that speed up or slow its development (accelerators).

\section{Shared Purpose as the Core}

The essence of the model we propose lies in the generation of a shared and common business purpose, one that pivots on a triad of knowledge, motivation, and action. ${ }^{1}$ In other words, for a business purpose to be shared, it must be such that it illuminates the mind (knowledge), captivates the heart (motivation), and guides the daily work of the organization's employees (action): illuminating, captivating, and guiding are the three elements that must characterize the business purpose so that it becomes internalized by all (Fig. 10.2). 


\section{SHARED PURPOSE}

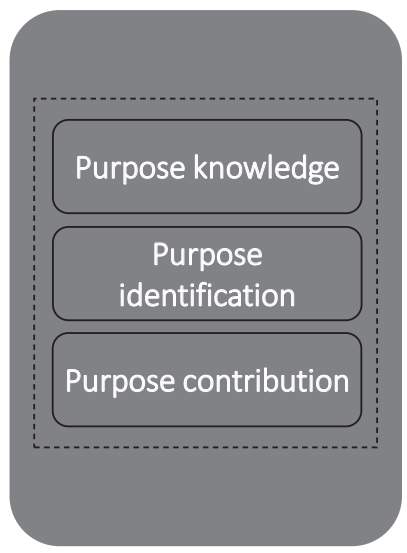

Fig. 10.2 Shared purpose and its dimensions

However, it must be recalled that the generation of this shared purpose is a lengthy, continuous process and, at times, an unstable equilibrium.

It is a lengthy process because purpose is not something one should define from a top-down view and expect others to internalize immediately. All too often, organizations have a very well-defined purpose that is announced clearly and yet, at the same time, we often still encounter many within teams who hardly identify with it. Identification is a key word. Organizational purpose and the manner in which it is generated are quite important. The existence of sincere dialogue within the team achieves a climate of trust and helps people open up and share their individual purposes. This is vital in building common purpose- a purpose that comes to be shared by everyone.

But, how well do we know the individual purposes of the people who work in our organization? Do we provide them space, so that they can think about and define their individual purpose? Once done, do we respect and acknowledge that purpose? Do we create environments where people feel comfortable and share their purpose? And do managers lead the way by sharing their own purpose? Certainly, answering such questions requires significant time, not to mention enough serenity to even raise them. For this reason, the process takes time. Consider this "the cost." The advantage? It is quite clear: as the organization invests time in the generation of shared purpose, the door will open for team members to identify with the purpose and assume it as their own, thereby increasing commitments throughout the organization.

Yet, it is important to remember that the creation and connection of purpose is a continuous process. Endless, one might say. There are at least two 
reasons for this: first, because circumstances change and just as the organization needs to continually adapt to the environment, the purpose must also adapt to these new circumstances. This is not to say that an organization's purpose is like a weather vane. What it means, however, is that as the environment evolves, it will require that organizations adapt and revalidate to ensure that their purpose relates to new market demands. Second, shifts in personnel bring new staff to teams. With the integration of new team members, maintaining an ongoing dialogue becomes increasingly important so that purpose remains common and shared.

Finally, shared purpose, its creation and proliferation, can be an unstable equilibrium. This becomes most notable when trying to manage the balance between employees' day-to-day requirements and their sense of purpose. Running the business from a genuine perspective of purpose requires a balance between the short and long view. The patience required for purpose and the pressure demanded by results drives a wedge that creates tension: if we focus only on the day-to-day routine, we distance ourselves from the purpose and if we focus only on purpose, sometimes we risk losing sight of the shortterm business requirements. This tension necessitates knowing how to manage this instability, such that we live our everyday life with a sense of purpose, yet live our purpose with a sense of everyday life.

For these reasons, it is especially important to have tools for measuring and assessing the degree to which the organization is purpose-oriented, as intuition does not always go hand-in-hand with reality. It happens rather often that upon measuring, managers are amazed to find their efforts are not producing the expected results or, even worse, they are actually regressing. Of course, it also happens that some managers are pleasantly surprised to see their efforts yielding better results than expected. Maintaining a high level of purpose (something that should be natural in all organizations) requires taking the pulse of the organization frequently, without ever letting down one's guard. The more we are able to bring shared purpose into our sphere of work, the greater will be the effects and consequences for organizations.

\section{Consequences of Having a Shared Purpose}

From the perspective of the individual in the organization, we can distinguish at least three consequences of having a shared purpose: it increases commitment, proactivity, and extra-role behaviors (Fig. 10.3).

Several authors assert that commitment, first and foremost, expresses the link established between the person and the organization. ${ }^{2}$ More specifically, 


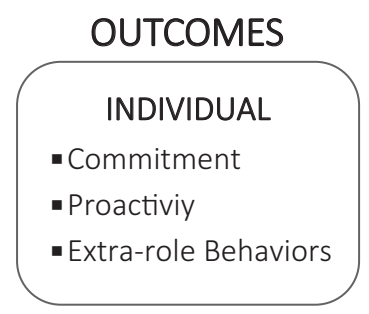

Fig. 10.3 Individual outcomes of having a shared purpose

that shared purpose generates what is called affective commitment, ${ }^{3}$ that is, the emotional bond that causes employees to stay in an organization because it feels like their own. There are also numerous studies that relate affective commitment to a decrease in rotation and absenteeism, ${ }^{4}$ an increase in employee satisfaction, ${ }^{5}$ as well as an increase in productivity and organizational performance. ${ }^{6}$

While commitment is a connection, proactivity is a disposition-an attitude of wanting to contribute to the organization's goals. ${ }^{7}$ In this case, employees feel a certain ownership, and also wish to contribute to advancing the shared purpose because they identify with it.

Finally, the third individual-level consequence is the generation of extrarole behaviors. ${ }^{8}$ That is the phenomenon in which employees willingly take on more than is required. It is a clear indication that people identify with the organization's purpose as their own. But when purpose fails to change behaviors or express itself in concrete ways, it is neither as shared nor as internalized as had been thought.?

In addition to individual consequences, shared purpose has consequences that impact the organization at a collective level. Some authors have stressed the importance of measuring the impact of purpose on a Unity-Profit ${ }^{10}$ curve. "Unity" is the variable that measures the degree to which company members identify with a given purpose, and "Profit" is understood as the company's economic result. As shown by previous research, these two variables are not by themselves orthogonal, but, when analyzed together, they allow us to see what type of organization we are generating. ${ }^{11}$ For example, the organization with an effective purpose will result in high levels of the two variables and often exhibit extraordinary culture, compared to organizations that have only high levels of unity (paternalistic cultures), or only seek profitability (aggressive cultures), or low levels of both (bureaucratic cultures) (Fig. 10.4).

In light of such positive consequences resulting from the creation of shared purpose, we may ask ourselves, how best to achieve it? What tools can we deploy to enhance our purpose strength? 


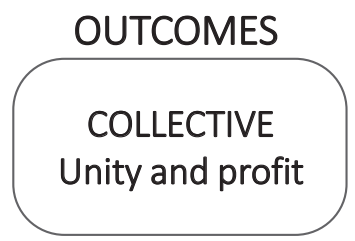

Fig. 10.4 Collective outcomes of having a shared response

\section{Antecedents of Shared Purpose}

In order to best structure an organization from a perspective of purpose, it is important to understand the logic that governs this process. We believe that the metaphor of the gardener describes it best. How do you grow a plant? Certainly not by stretching it, for if you do, it may damage the stem and perish. The art of gardening consists of creating and sustaining a suitable environment so that the plant can grow robustly. This concept applies to organizations and their design as well. Just as the gardener selects, waters, and fertilizes the land, we must work the organizational drivers within our control.

However, one should not expect that by simply managing these drivers will result in an immediate effect. What can be expected is the generation of a working environment where people become increasingly aware of their role in the bigger picture, which in turn helps the purpose become more common and shared by everyone. These are the levers to be pulled. There are, at least, four key organizational levers on which we can act to design a purposeoriented organization: strategy, systems, leadership, and communication (Fig. 10.5).

Strategy marks the way forward, but the real goal here lies in defining the strategy in such a way that unambiguously points the organization toward its stated purpose. This can be reinforced through the use of purpose-oriented objectives that make the strategy real and relatable to the purpose. It has been said that "purpose without objectives is a dead purpose. Likewise, objectives without purpose are blind objectives." 2 Purpose will not only help to provide a reason for working every day, but it also prioritizes our work putting emphasis and energy on those objectives that answer the company's call. From this perspective, strategy will be more coherent and authentic to the extent that it helps put into practice the organization's purpose.

The systems of a company are its policies and procedures, those that guide its people in their day-to-day work and move them down the path set out by its strategy. One of the aims of a management system should be to ensure that the organization's purpose is noticed, and becomes part of and gives meaning 


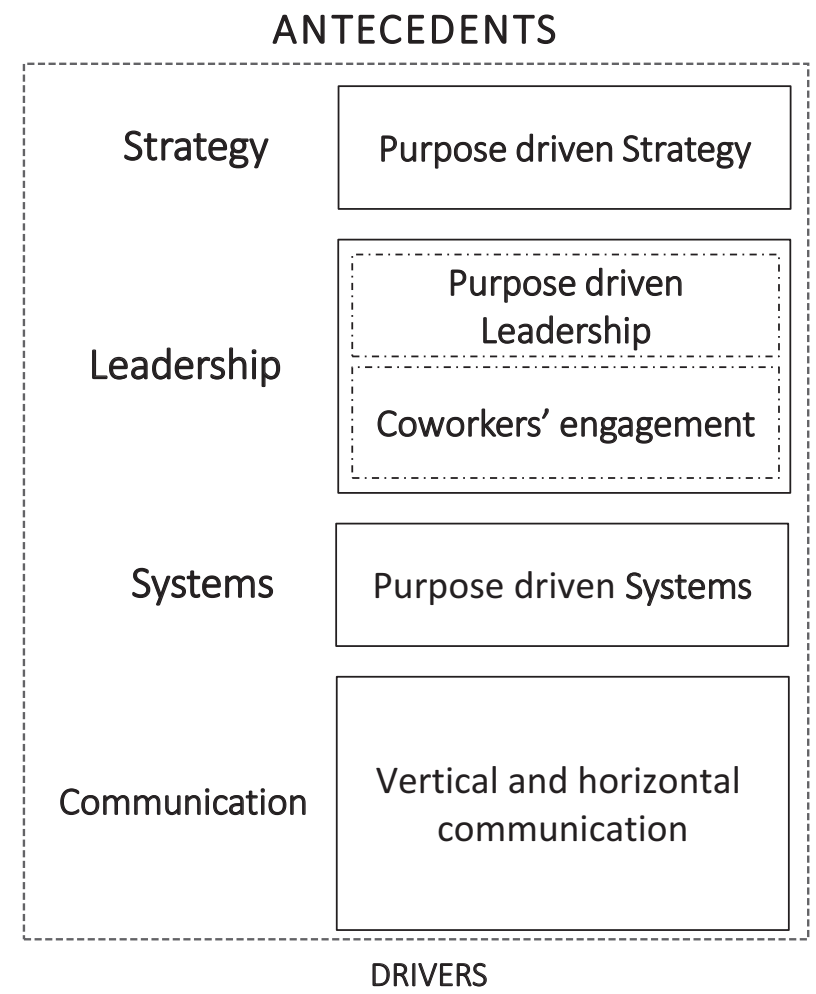

Fig. 10.5 Organizational drivers that precede the shared purpose generation

to daily work. The whole point about this is that "purpose" makes no difference, unless it changes the way people operate or the way they do business. ${ }^{13}$ Recruitment, training and development, task planning, performance evaluation, incentive systems, budget management, and the rest of the company's policies should be focused on developing and enhancing the shared and common purpose. Otherwise, purpose becomes nothing but a slogan that appears on the website, appealed to in official speeches, but not very fertile as it lacks presence in people's day-to-day reality. The core of any management system is that it drives the dynamics of the organization and that it has an impact on the employees' daily activities to the point that employees might say: "I'm not here simply to achieve some objectives; instead, my work is oriented towards achieving the company's shared purpose."

Leadership is another major driver of shared purpose. A purpose-oriented organization requires leadership capable of reaching the hearts and minds of co-workers by generating an understanding that working for the common purpose is worthwhile. ${ }^{14}$ Two types of leadership can be distinguished. On the 
one hand, there are managers and executives who promote the purpose, leading by example. This is recognized by co-workers and employees as authentic and coherent. Real leaders succeed in getting their people to strongly accept their words yet freely adhere to the organizational purpose. Recognizing and valuing the differences of each person within the organization, generating work teams in which cooperation takes precedence over competition, promoting co-creation, continuously appealing to the common purpose as the main motivating reason for day-to-day work, and delegating responsibility so that workers assume the mission of furthering the purpose-all are actions that depend on the organization's leadership capacity. On the other hand, it is equally important that there exists a form of shared leadership: the kind of leadership that is exercised at all company levels and in all of its areas, in which co-workers mutually reinforce the transmission and identification with the organization's purpose..$^{15}$

Finally, consistent communication is a fundamental tool for transmitting organizational purpose in such a way that illuminates and fascinates all involved. Considering this as a driver, organizations must ensure the appropriate channels exist to, not only transmit the message, but also to show that decisions are justifiably based upon it. One of the design challenges is that organizations should be able to capture communication upwards. The key is to be able to grasp organizations' feelings and thoughts and, in turn, promote purpose as part of an overall internal dialogue.

Measuring these four variables — strategy, systems, leadership, and communication-will allow leaders to understand the extent to which the company is properly managing those organizational levers that promote a shared purpose.

\section{Accelerators (or Decelerators) That Impact Shared Purpose}

Accelerators, or decelerators, are aspects that either positively or negatively impact the influence the drivers have on specific people within the organization. They must be understood and taken into account because they play a role in the effectiveness of the antecedents of purpose. Likewise, understanding and knowing how best to boost the drivers will make them more impactful (Fig. 10.6).

There are four determining factors that should be considered: trust between managers and workers, values held by team members, their motivations, and each employee's purpose. 


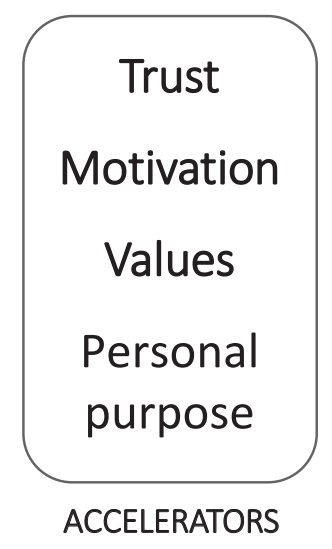

Fig. 10.6 Accelerators (or decelerators) of shared purpose generation

Some authors define trust as the decision to make oneself vulnerable to another person by assuming the risk of depending on that other person. ${ }^{16}$ Being vulnerable allows for more authentic and stronger relationships. ${ }^{17}$ Showing that we have made a mistake, opening up to others, sharing the aspects that are important to us, what motivates us, or our personal purpose, are evidence of making ourselves vulnerable. ${ }^{18}$ In this way, trust determines the relationship between the background and the creation of a shared purpose because, so long as there is trust, the resulting work environment will provide psychological safety, ${ }^{19}$ making it easier for people to open up and show themselves as they truly are. The generation of trust will facilitate getting to know the real person behind each character, ${ }^{20}$ to know and recognize their uniqueness and to treat them in a more authentic way.

Values and motivation express the deepest aspects of people, the ideals that govern their behavior, and the motives that drive them to act. We adhere to the proposals of authors who identify four types of values among an organization's employees: increasing economic benefits, creating a comfortable relationship environment, developing personally and professionally, and ultimately contributing to the larger society. ${ }^{21}$ Pérez-López identified three types of motives ${ }^{22}$ : extrinsic ones, or what is received from outside (salary, recognition, fame, etc.), intrinsic ones, or what is acquired (learning, satisfaction, competences, virtues, etc.), and, finally, transcendent ones, or that which is given to others (service, caring, etc.). People's values and motives will influence the creation of the shared purpose. Thus, for example, it will be easier to generate a shared purpose with people who have transcendent motives and among whom contribution values prevail, rather than with others whose motives are primarily extrinsic or intrinsic. ${ }^{23}$ 
Finally, each employee's personal purpose will also influence the generation of common and shared purpose. ${ }^{24}$ Having invested time in searching for, reflecting on and defining a personal purpose, one that gives meaning to dayto-day life, makes it easier to share as well as to analyze the extent to which the organization's purpose encompasses the personal one. The more meaning and purpose, the easier it will be for people to share and identify with the organization's common purpose.

\section{Assessing in Order to Be Able to Improve}

In this chapter, based on our experience and research, we have outlined the components of our Purpose Strength Model (see Fig. 10.1): a model that shows how certain variables are articulated around a shared purpose and establishes the basis for the development of a diagnostic tool.

From this model, having reliable and validated questionnaires for measuring the variables of the model will allow us to assess and to take to the pulse of an organization. These evaluations will allow us to be aware of the degree to which an organization has a purpose that gives meaning and guides day-today activities. Moreover, statistical analysis can help us to understand how the variables are related between themselves and to establish concrete plans that help boost it, measuring the progress and impact that the implemented actions have on the organization over time.

We do not consider this proposal to be a closed model. Future research will allow us to expand its scope and depth by including new variables, such as taking into account the purpose of other stakeholders, customer satisfaction, favorable purchasing attitudes, and the reputation or the relevance of the corporate brand.

That future research may indicate adjustments to our model does not dissuade us; indeed, this idea fascinates us. The ability to expand the frontiers of knowledge on how to generate inspiring organizations drives us. This is our goal: to deepen our understanding of the dynamics of developing purposedriven organizations, to generate practical tools that make this a reality, and to help companies generate more sustainable work environments that combine unity and profit.

\section{Notes}

1. Rey, C., \& Bastons, M. (2018). Three dimensions of effective mission implementation. Long Range Planning, 51(4), 580-585. 
2. Meyer, J. P. (2016). Handbook of employee commitment. Northampton, MA: Edward Elgar Publishing.

3. Lofquist, E. A., Isaksen, S. G., \& Dahl, T. J. (2018). Something fishy: Exploring change, job engagement and work environment in the Norwegian Directorate of Fisheries. Journal of Change Management, 18(4), 1-23.

4. Mathieu, J. E., \& Zajac, D. M. (1990). A review and meta-analysis of the antecedents, correlates, and consequences of organizational commitment. Psychological Bulletin, 108(2), 171-194.

5. Meyer, J. P., Allen, N. J., \& Smith, C. A. (1993). Commitment to organizations and occupations: Extension and test of a three-component conceptualization. Journal of Applied Psychology, 78(538), 538-551.

6. Dayan, M. (2010). Managerial trust and NPD team performance: Team commitment and longevity as mediators. Journal of Business \& Industrial Marketing, 25(2), 94-105.

7. Griffin, M. A., Neal, A., \& Parker, S. K. (2007). A new model of work role performance: Positive behavior in uncertain and interdependent contexts. Academy of Management Journal, 50(2), 327-347.

8. Motowidlo, S. J. (2000). Some basic issues related to contextual performance and organizational citizenship behavior in human resource management. Human Resource Management Review, 10(1), 115-126.

9. Lofquist, E. A., Isaksen, S. G., \& Dahl, T. J. (2018). Something fishy: Exploring change, job engagement and work environment in the Norwegian Directorate of Fisheries. Journal of Change Management, 18(4), 1-23.

10. Cardona, P. \& Rey, C. (2008). Management by missions. New York: Palgrave Macmillan.

11. Kotter, J. P. (2008). Corporate culture and performance. New York: Simon \& Schuster.

12. Cardona, P., \& Rey, C. (2008). Management by missions. New York: Palgrave Macmillan.

13. White, A., Yakis-Douglas, B., Helanummi-Cole, H., \& Ventresca, M. (2017). Purpose-led organization: "Saint Antony" reflects on the idea of organizational purpose, in principle and practice. Journal of Management Inquiry, 26(1), 101-107.

14. Marimón, F., Mas-Machuca, M., \& Rey, C. (2016). Assessing the internalization of the mission. Industrial Management \& Data Systems, 116(1), $170-187$.

15. Cardona, P., \& Rey, C. (2009). El liderazgo centrado en la misión. Harvard Deusto Business Review, 180, 46-56.

16. Mayer, R. C., Davis, J. H., \& Schoorman, F. D. (1995). An integrative model of organizational trust. Academy of Management Review, 20(3), 709-734.

17. Brown, B. (2012). The power of vulnerability. Louisville, CO: Sounds True.

18. Lleó de Nalda, A., Guillén, M., \& Gil Pechuan, I. (2016). The influence of ability, benevolence, and integrity in trust between managers and subordi- 
nates: The role of ethical reasoning. Business Ethics: A European Review, 25(4), 556-576.

19. Edmondson, A. C. (2018). The fearless organization: Creating psychological safety in the workplace for learning, innovation, and growth. Hoboken, NJ: Wiley.

20. Guillén, M., Lleó de Nalda, A., \& Marco Perles, G. (2011). Towards a more humanistic understanding of organizational trust. Journal of Management Development, 30(6), 605-614.

21. Malbašić, I., Rey, C., \& Potočan, V. (2015). Balanced organizational values: From theory to practice. Journal of Business Ethics, 130(2), 437-446.

22. Pérez López, J. A. (2014). Foundations of management. Madrid: Rialp.

23. Chinchilla, N., Jiménez, E., \& García-Lombardía, P. (2018, April 16). Integrar la vida: Liderar con éxito la trayectoria profesional y personal en un mundo global. Editorial Ariel.

24. Hanson, J. A., \& VanderWeele, T. J. (2019). The comprehensive measure of meaning. Harvard University Technical Report.

Open Access This chapter is licensed under the terms of the Creative Commons Attribution 4.0 International License (http://creativecommons.org/licenses/by/4.0/), which permits use, sharing, adaptation, distribution and reproduction in any medium or format, as long as you give appropriate credit to the original author(s) and the source, provide a link to the Creative Commons licence and indicate if changes were made.

The images or other third party material in this chapter are included in the chapter's Creative Commons licence, unless indicated otherwise in a credit line to the material. If material is not included in the chapter's Creative Commons licence and your intended use is not permitted by statutory regulation or exceeds the permitted use, you will need to obtain permission directly from the copyright holder. 